\title{
The CT Angiographic Prevalence of Renal Accessory Arteries in Kenya
}

\author{
Richard Sungura $^{1} *$, Callen Onyambu ${ }^{2}$ and Ian Mathenge ${ }^{2}$ \\ ${ }^{1}$ Department of Radiology and Imaging, Mount Meru Referral Hospital, Arusha, Tanzania \\ ${ }^{2}$ Department of Diagnostic Imaging and Radiation Medicine, University of Nairobi, Kenya
}

*Corresponding author

\section{Keywords}

Accessory renal artery, Renal donor, CT angiography

Article Info

Accepted:

20 December 2017

Available Online:

10 January 2018

\section{A B S T R A C T}

The understanding of vascular anatomy of kidneys has gained remarkable significance in both medical and surgical disciplines. The science of renal transplantation intensifies a need for recognizing the variation in renal vascular anatomy in different population and ethnicities. CT angiography is a less invasive modality for assessing the renal vascular anatomy of potential kidney donors as not every healthy person wishing to donate kidney is a suitable candidate for this highly specialized procedure. Difficulty in surgical anastomosis of vessels has been reported because of anatomical complexity. There is diversity in anatomical variation in different population, ethnic group and geography. In Kenya not much work has been done in this area using living donors. The aim of this study was set to determine the prevalence of renal accessory arteries among African adults in Kenya and establish the kidney side commonly presents with accessory arteries. The study was a three-year cross sectional descriptive study conducted at Kenyatta National Hospital from June 2008 to June 2011. A total of 204 cases including 103 (50.5\%) females and 101 $(49.5 \%)$ males were recruited for CTA. The mean age of participants was 47.16 years (SD 18.32). The prevalence of accessory arteries was $11.3 \%$ and prevalence of left sided accessory arteries (7.4\%) was higher than right-sided accessory arteries $(4.9 \%)$. The radiological prevalence of Accessory renal arteries among African adults in Kenya is more than $11 \%$ left kidney commonly presents with unilateral accessory renal arteries more than the right kidney.

\section{Introduction}

The vascular anatomy of kidneys is very important both medically and surgically, especially in the era of renal transplantation procedures. Classically, each kidney is supplied by a single renal artery and a single renal vein, arising from the abdominal aorta and draining into the inferior vena cava, respectively. Anatomical variation is a common finding in renal vasculature where more than one artery supplying a kidney is the most common arterial variation, and this is seen in about $24 \%$ of cases (Sheo et al., 2010). These arteries are divided into two groups: hilar (accessory) and polar (aberrant) arteries. The accessory arteries enter the kidney from the hilum along with the main renal artery. 
Presence of Accessory renal arteries however has shown diverse prevalence with different ethnic and geographical variation, for example it has been reported that there are differences in the incidence of accessory arteries according to ethnic origin (African, 37.1\%; Indian, 17.4\%; Caucasian, 35.3\%; and "Colored" 18.5\%) (Satyapal, 2001). In Korea the incidence of multiple renal arteries has been reported as 18 to $30 \%$ in cadaveric organ procurement (Choi, 1997).

The current medical advancement in renal transplantation procedures has intensified the need for the understanding of renal vascular anatomy in different populations as a necessary preparation for kidney donation. Potential kidney donors may be disqualified as living donors due to their complex vascular anatomy and other complications.

In the study by (Ghonge et al., 2014) it was revealed that a total of $27 \%(n=132)$, the radiographic abnormality was the main reason for donor rejection. In these patients, renal stones (39\%) were the most common radiographic abnormality, followed by parenchymal abnormalities (29\%) and renal artery abnormalities (27\%). Therefore, detailed knowledge and understanding of surgical techniques is essential to attain these objectives in a renal transplant program.

Pre operative detection of Accessory arteries remains to be a challenge. A study that was done in China suggests that a Multi Detector CT (MDCT) scan can miss those Accessory arteries that are below $1.5 \mathrm{~mm}$ in diameter. But when they are larger than $1.5 \mathrm{~mm}$ then depiction is $100 \%$ as per study by (Zhan Jiqing et al., 2010). Therefore, when compared to surgery, the detection of accessory arteries in MDCT images was $85.7 \%$ but increases to $100 \%$ when vessels are more than $1.5 \mathrm{~mm}$ in diameter size.
Studies show that CT and MR angiography of the renal arteries in renal donors demonstrate substantial agreement. Inter observer disagreement in the interpretation of CT and MR angiograms is related to $1-2 \mathrm{~mm}$ diameter vessels (Ethan, 2000). There was a need to perform a study for surveying the pattern of renal vascular anatomy among the Kenyan population using CT scan as it has been known to have high degree of accuracy and is less invasive compared to the gold standard Catheter Angiography. The modern CT Scans have many reconstructions options such as maximum intensity projection (MIP) and volume rendering (VR) which provides better information, the option of windowing can as well help subtraction of masking structures like bones. The importance of such a study was further accelerated by the existing scarcity of such vascular data in most of African countries bearing in mind that renal arterial pattern have shown wide ethnic and geographic variations. Currently in Kenya the procedures of renal transplantation are done locally. The radiological information is mandatory initial investigation for renal transplantation. The only study of renal vascular system for the local population was done through postmortem cadaveric specimens by (Ogeng'o et al., 2010) concluded that over $14 \%$ of the Kenyan population may have additional renal arteries while more than $20 \%$ show early branching (Ogeng'o et al., 2010). It was vital then to do a similar study using imaging techniques to study the living cases, as the study that was done using cadavers did not address anatomical variation of arteries basing of renal sides. The kidney side is an important consideration during surgical planning to harvest and anastomose donor's kidney as the arterial and venous length is side dependent (Grant et al., 1998).

Therefore the objective of this study was to determine percentage of renal accessory 
arteries among Africans in Kenya and also to establish which side is commonly presenting with accessory arteries.

\section{Materials and Methods}

A Cross Sectional Descriptive Study was conducted at Kenyatta National Hospital department of radiology. Adults between the ages of 18 to 75 years were included in the study. These were all cases of patients and donors who were sent to the departments of Radiology to undergo either CT Renal angiography as potential kidney donors or any other Abdominal CT angiography for other reason apart from kidney and vascular pathology between the periods of June 2008 to June 2011.

Patients were excluded when they were found to have gross renal disease. Additionally, patients with CT angiography bearing evidence of ectopic kidney and other gross renal anomalies were not recruited. People who were found to have poor functioning kidneys or incidental hydronephrosis were not part of the study. People who lived in Kenya but were not of an African race were excluded. Lastly all cases CT angiography under the age of 18 years and above 75 years old were excluded.

The sample size was obtained from the use of statistical formula by (Fisher et al., 1998), at the confidence interval of $95 \%$ and a margin error of $5 \%$ and prevalence of presence of accessory renal arteries at $15 \%$ (Subhash et al., 2007), (Ogeng'o et al., 2010). The sample size was calculated as

$$
\mathrm{N}=\frac{\mathrm{Z}^{2 *(\mathrm{p}) *(1-\mathrm{p})}}{\mathrm{c}^{2}}
$$

Where $\mathrm{p}$ is proportion of prevalence, $\mathrm{Z}=$ standard normal distribution, $C$ is the level of significance desired. When this formula applied at $\mathrm{c}=0.05, \mathrm{z}=1.96$ and $\mathrm{p}=0.15, \mathrm{~N}=$ 195 cases of renal angiography. However 204 cases were sampled in this study. Renal and other abdominal CTA images were retrieved from the computer system and carefully examined for their renal vascular anatomy.

Patients' data including numbers and type of examinations were traced from the departmental registration book. Amount of contrast that was given was also traced from procedure book usually documented by the technologist on duty. Using this basic information the images of the patients were retrieved from the computer, scrutinized for its vascular anatomy, and the results documented in the designed data forms for analysis.

\section{Data analysis}

Data analysis was conducted using statistical package for social scientists (SPSS) version 15. The characteristics of study participants e.g. age and sex were summarized using descriptive statistics. T-tests were used to compare renal findings between different patient groups. Data were presented in form of graphs, pie charts and tables. Radiological images are presented for selected cases.

\section{Results and Discussion}

A total of 204 cases undergoing CT angiography at Kenyatta national hospital $(\mathrm{KNH})$ were recruited in this study. The basic demographic characteristics of these cases are summarized in the section below.

\section{Demographic characteristics}

The study sample comprised 103 (50.5\%) females and $101(49.5 \%)$ males giving a maleto-female ratio of approximately $1: 1$. The mean age of the cases investigated was 47.16 years (SD 18.32). The age range of the study 
cases was 18 years to 75 years. The average age of male patients was 47.92 years (SD 18.23) and the average age of female patients was 46.41 (SD 18.46). There was no statistically significant difference in the age of male compared to female patients $(t$ statistic $=$ $0.58, \mathrm{p}$ value $=0.56$ ). The percentage distribution of the cases is presented in Figure 1. The study cases were similarly distributed across the different age groups. Most of the cases were in the youngest age group below 30 years constituted $21.4 \%(n=43)$ of the cases. The remaining age groups each ranged between $13.4 \%$ and $18.9 \%$ of the total number of cases.

\section{Prevalence of renal accessory arteries}

The radiological prevalence of accessory renal arteries among the African cases included in this study was $11.3 \%$. As shown in Figure 2, this represented 23 out of the 204 participants. Among these 23 cases who had accessory arteries, 7 (3.5\%) cases had unilateral left accessory arteries, 5 (2.5\%) had unilateral right accessory arteries, two $(0.98 \%)$ patients had bilateral accessory arteries and one $(0.5 \%)$ case had two left accessory arteries.

The overall prevalence of presentation with a left accessory renal artery was slightly higher among cases compared to the presentation with a right accessory renal artery. Fifteen (7.4\%) of the cases had a left accessory artery compared to $10(4.9 \%)$ of the cases presenting with a right accessory artery. However, this difference in the prevalence of presentation with right or left accessory arteries was statistically significant when the percentages were compared using a two sample test of proportions (difference $=2.5 \%, z$ statistic $=$ $1.03, \mathrm{p}$ value $=0.3$ )

Figure.1 Percentage distribution of age among patients undergoing CT angiography in $\mathrm{KNH}$ (Kenyatta National Hospital)

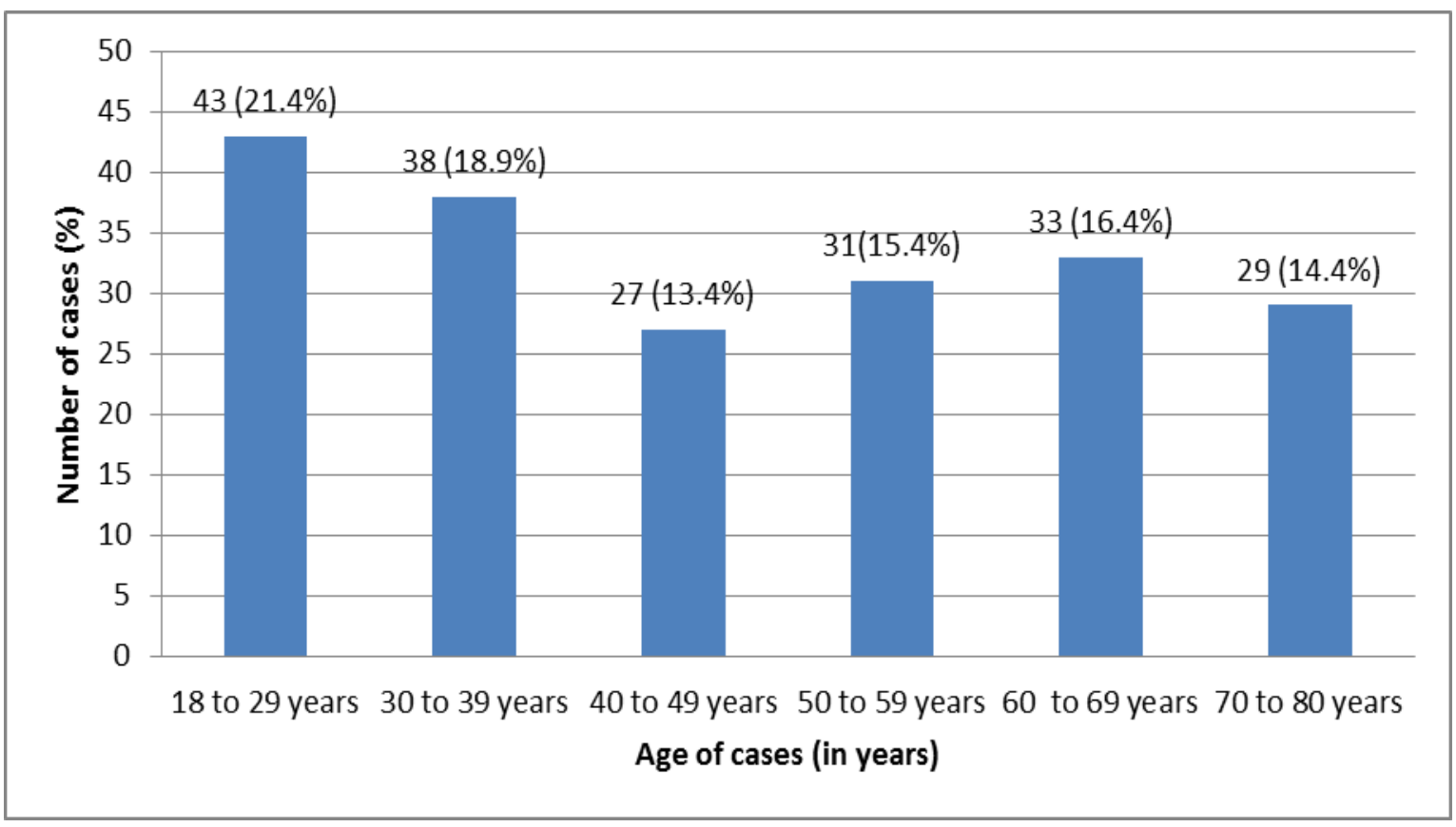


Figure.2 Prevalence of radiological confirmed accessory renal artery in African cases at KNH

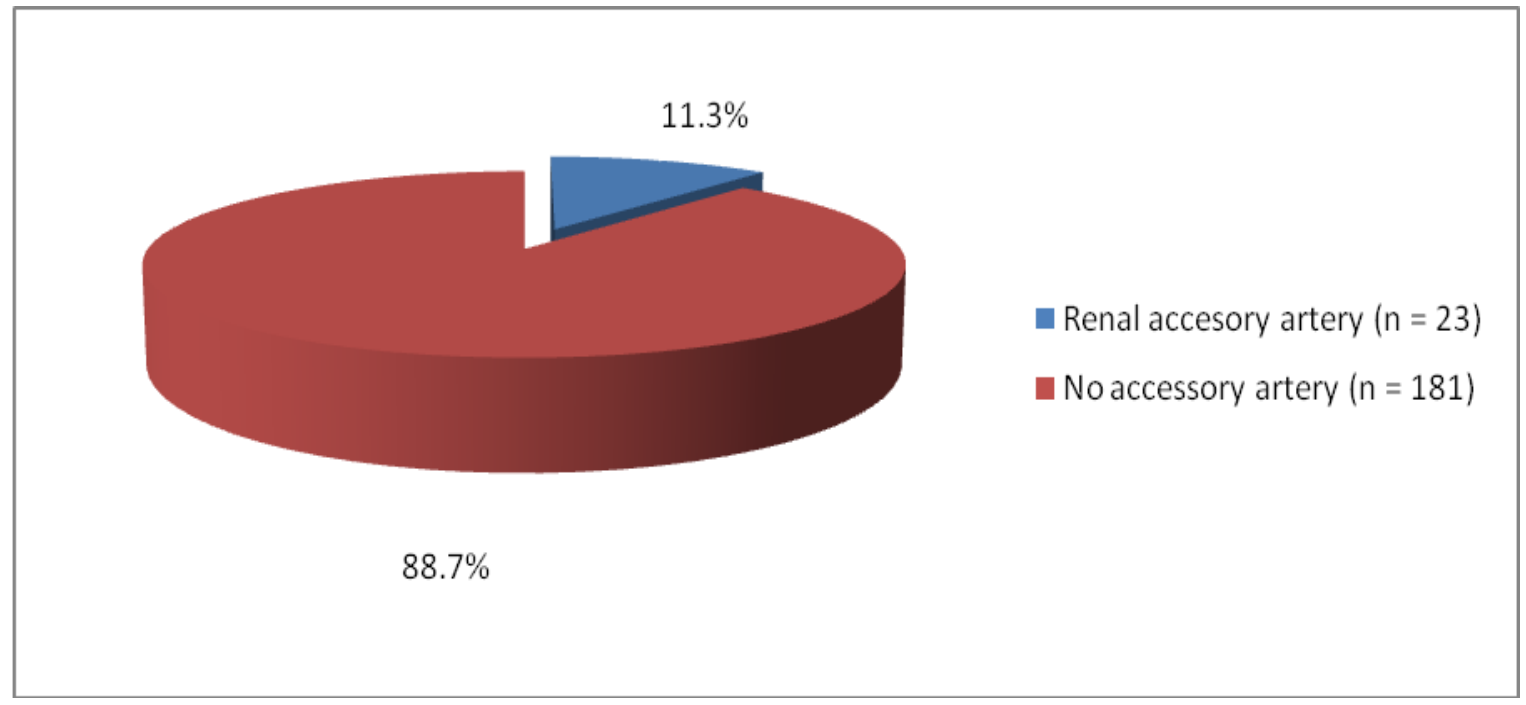

Fig.3 Image of potential kidney donor at $\mathrm{KNH}$ presented in volume rendering reformat. Left nephrectomy was done thereafter. Bone removal application node done

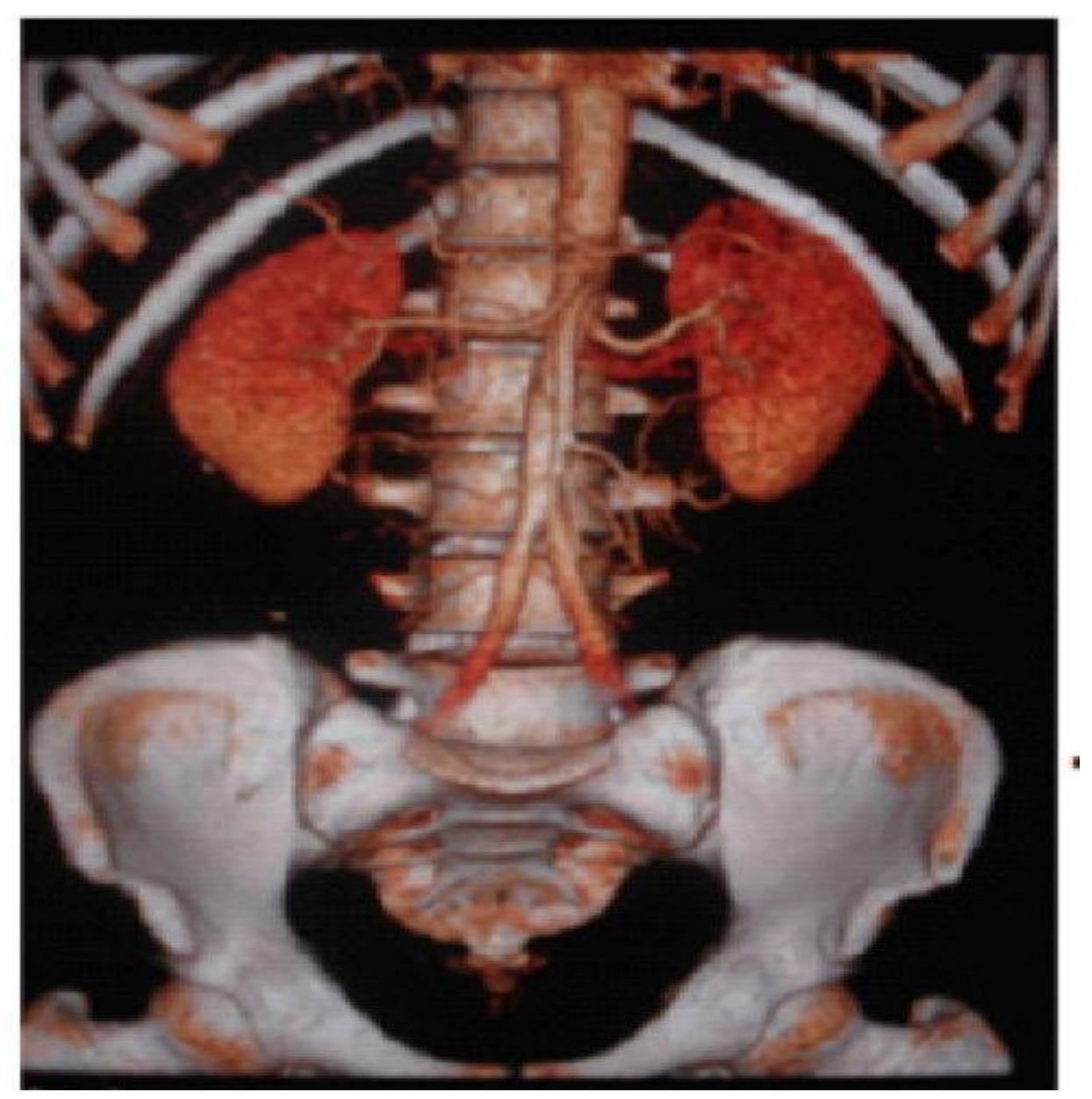


Figure.4 MIP Renal CTA image of potential kidney donor with left accessory artery. Bone removal application was done to clear superimposition

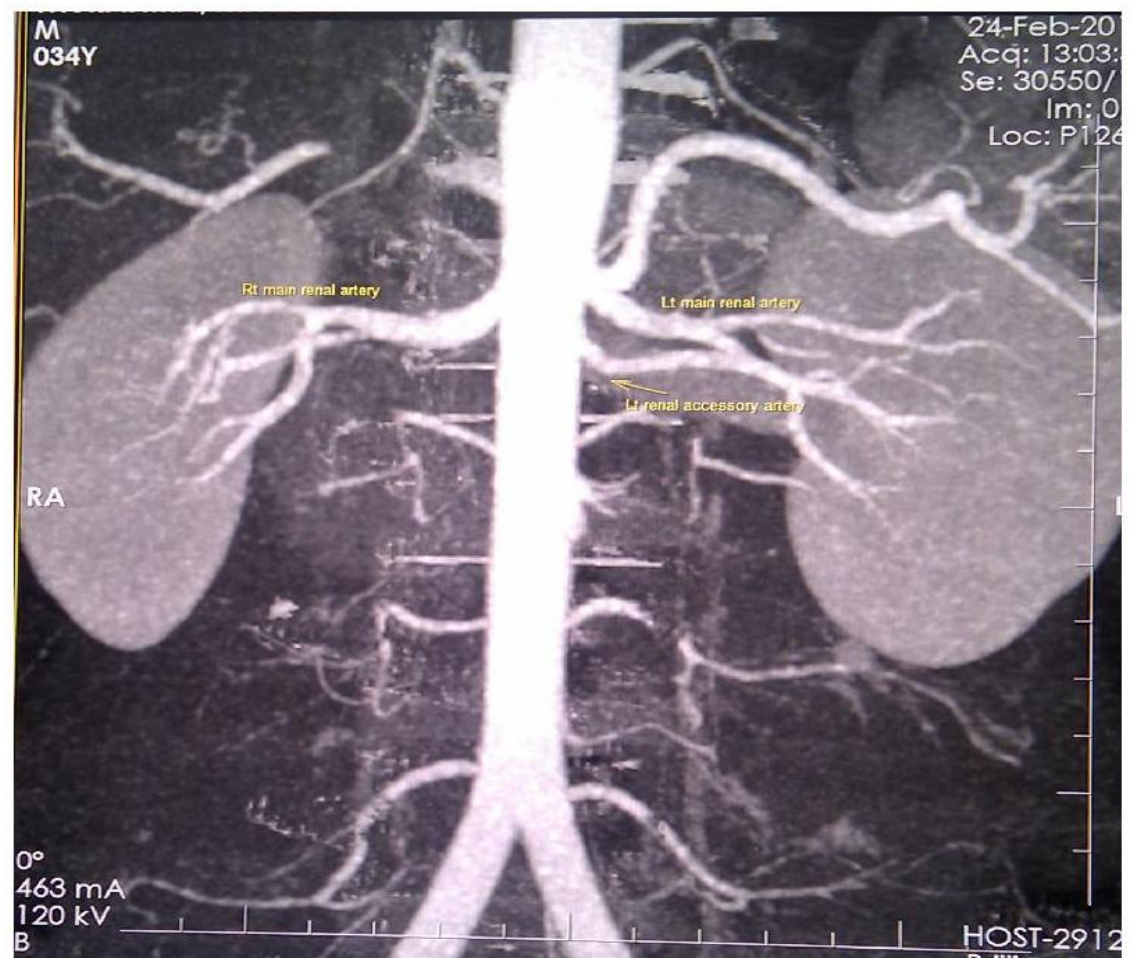

Figure.5 Volume rendering CTA image showing left accessory artery. Bone removal application was bone

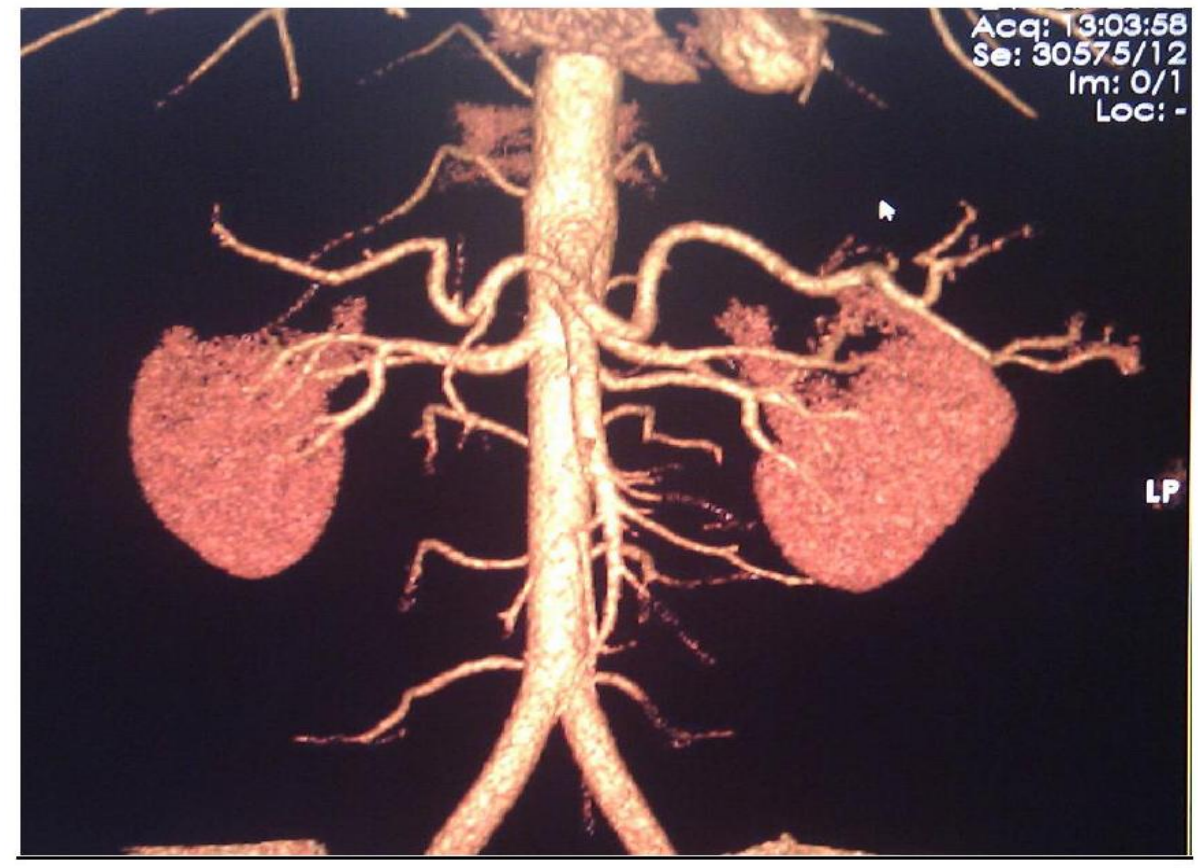


Figure.6 Axial CTA at delayed phase. This potential donor was rejected following right hydrocalycosis as a result of pelvi ureteric junction obstruction in the right side

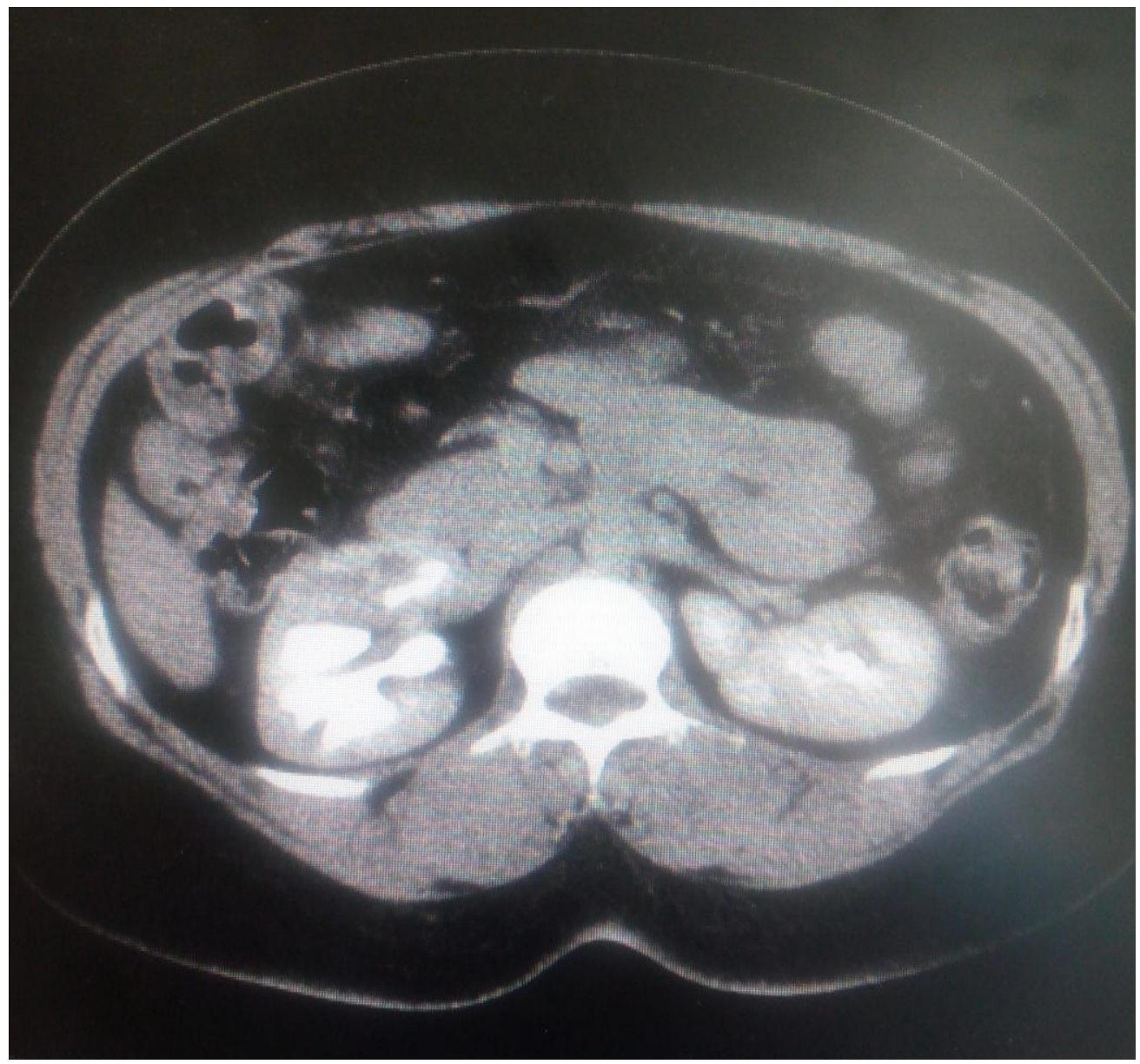

A total of 204 cases were recruited in this three-year cross sectional study done at Kenyatta National Hospital in Nairobi, Kenya. The sample was composed predominantly of adults with a mean age of 47.16 years (SD 18.32) and range of 18 years to 75 years and the ratio of male to female participants was 1:1. These findings are of clinical significance because renal donors are commonly adults with similar demographic characteristic to that reported in the current study. Thus the similarities reported above increases the relevance of the results from this study.

The Computerized Tomography Angiography findings from the study are discussed below under the following sub-headings: prevalence of accessory arteries; relation between kidney side and accessory arteries; relation between main arterial caliber and accessory arteries and extra renal branching.

\section{Prevalence of accessory arteries}

In this study it was found that the prevalence of accessory arteries among the black African population in Nairobi, Kenya is $11.3 \%$. There was also a predominance of left-sided accessory arteries. The results reported above in general correlate with the findings in the study done by (Ogeng'o JA et al., 2010) who observed $14.3 \%$ prevalence in a Kenyan autopsy study. The minor differences in 
prevalence between the two studies could possibly be explained by two factors. Firstly, the possibility that our study was specific for the black African Kenyans compared to all autopsy cases in Kenya regardless of their race. Secondly, autopsy and intraoperative studies involve direct visualization which could give high pick up rate compared to this radiological study. In fact studies have demonstrated that there is possibility of missing small accessory arteries at radiology which may be demonstrated intra-operatively (Zhang J et al., 2010).

\section{Study limitations}

This study faced some limitations as patients' data collection and retrieval was seriously limited by the lack of long term computerized information archiving system such as PACS. Lack of finance was a major limiting factor, since it could require a lot of funds to pay for the patients for other alternative imaging modalities in order to achieve a comparative study. It was very difficult to achieve a representative sample size by performing this study specifically for those who came for precisely CT renal angiography for pre transplantation evaluation, therefore recruitment of other patients who have been referred for other abdominal CT angiography to study renal vascular system may subject the study to some degree of errors due to presence of sub clinical medical conditions that may as well affect the quality of renal imaging.

Based on the radiological findings of this study and the objectives that were set, it is concluded that; the radiological prevalence of Accessory renal arteries among African adults in Kenya is more than $11 \%$ without gender predilection. The left kidney commonly presents with unilateral accessory renal arteries more than the right kidney. This information is significant because the renal harvesting side that is preferred by surgeons is the left due to its longer venous length ${ }^{(8)}$. Paradoxically in Kenyan population this is the side which also presents with the higher incidence of accessory arteries. This study therefore recommends knowledge transmission to surgeons about vascular reconstruction techniques as chances are always there to encounter vascular complexities. ${ }^{(11)}$

\section{What is already known}

It is already known that from the autopsy the known prevalence of accessory arteries in Kenya is $21.6 \%$ (Ogeng'o et al., 2010) Multi detector CT scan angiography is a useful tool in depicting accessory arteries for qualifying candidates for kidney donation.

\section{What is added from this research}

The radiological prevalence of accessory arteries in Kenya is $11.3 \%$. This finding is lower than the gold standard done by autopsy suggesting missing smaller arteries $<1.5 \mathrm{~mm}$ on CT scan. The surgically significant arteries are not missed at the optimum protocol of CT renal angiography.

\section{Recommendations}

A comparative study needs to be done in our set up to correlate radiological findings versus intra operative findings of the renal vascular anatomy for kidney donors for an acceptable period of time to cover wide sample size and assess the sensitivity of radiological tools like MDCT angiography. In such a study our protocol for Renal CTA can be revised to enable higher depicting rate. This study was done using 16 Slice Helical CT Scan; a similar study can be repeated using a higher grade machine in order to find out whether different pickup rate can be demonstrated. 


\section{Consent to publish}

All patients accepted to participate in this study and they were well informed of the plan to share the findings to other parties of the medical fields anonymously. This is to confirm that none of a participant name or identity has been revealed in this manuscript along with publication of this research work.

\section{Competing interests}

The authors declare that they have no competing interest in whichever situation related to publication of this study. There is no fund, fee or reimbursement received from any organization that may gain or lose financially upon publication of this document. None of the authors hold stock shares in any organization that may gain or lose from this publication. No application is made or intended to be done to any patents related to the context of this manuscript. We have no other financial or non financial competing interest politically, intellectually or commercially.

\section{Authors contributions}

Richard Sungura is the main and $1^{\text {st }}$ author of this document. He was the founder of the main idea for this study. He participated in formulating, writing drafts, following all procedural issues related to ethical steps for obtaining permission to conduct this research at the Kenya's national hospital KNH. He was finally responsible for making steps to publish this work to scientific journal. Ian Mathenge was the 2nd author and he contributed a lot in proof reading contents of this manuscript and in addition he helped the main author in refining data interpretation. Callen Onyambu is hereby known as 3rd author. She was the main supervisor from the University of Nairobi. She was the main reviewer of this work. She was responsible for making corrections, proof reading and reshaping the research proposal to come into effect. Upon submission of this work at the University of Nairobi during 2012 she is the one who encouraged the $1^{\text {st }}$ author to put this work into publication.

\section{Acknowledgement}

This study was made possible by the help of the following people whom I hope can accept my humble thanks. My supervisors Dr Onyambu and Dr Mathenge for their valuable guidance, advise and comments on this chosen topic for my Masters of medicine dissertation. Further appreciation be extended to the administration of Kenyatta national Hospital where data was collected and to the Belgian Technical Corporation-Tanzania office for financing my stay in Nairobi.

Many thanks are also extended to Mr Phillip Ayieko who did most of the statistical work and finally data interpretation of this book.

\section{Availability of data}

Data is available as part of the results section of this research. Further data can be available at the Kenyatta national hospital in Kenya archives. Nevertheless this study underwent all scholarly procedures and the findings are archived at the University of Nairobi main library and can also be accessed through Elibrary.

\section{References}

Sheo K, Zafar N, and Archna G. The utility of 64 Multi Detector CT Angiography for evaluation of the renal vascular anatomy and possible variation, Korean Journal of Radiology, 2010; 11(3): $346-354$.

Satyapal KS, Haffejee AA, Singh B, et al., Additional renal arteries: Incidence and 
morphometry. Surg Radiol Anat 2001; 23(1): 33-8.

Choi SS and Han DJ, Journal of Korean Society of Transplantation, 1997; 11(1): 81-94.

Ghonge NP, Satyabrat G, Vijaya R, MDCT evaluation of potential living renal donor, prior to laparoscopic donor nephrectomy: What the transplant surgeon wants to know?, Indian J Rdaiol Imaging. 2012; 24(4): 367-378.

ZHANG J, HU Xiao-peng, WANG Wei et al., Multidetector row - CT in evaluation of living renal donors, Chinese Medical Journal, 2010; 123(9): 1145-1148.

Ethan J. H, Donald G. M, Richard J. Wechsler et al., Preoperative Evaluation of Living Renal Donors: Comparison of CT Angiography and MR Angiography, Radiology, 2000; 216: 434-439.

Ogeng'o J.A, Charles O M, Simeon R S et al.,
Variant anatomy of renal arteries in a Kenyan population, Ann Transplant. 2010 Mar 19; 15(1): 40-5.

Grant I.S D, Michael E. S, Ruth A.M et al., Critical analysis of the laparoscopic donor nephrectomy in the setting of complex renal vasculature: Initial experience and intermediate outcomes, Journal of Endocrinology 2009; 23(3): 451-455.

Fisher S J and Fielder D G. A standard weight equation to assess the condition of North American lake herring, J Fresh water Ecol. 1998; 13: 269-277.

Subhash B, Michael C, Shubam G et al., Vascular disease management, Journal of invasive cardiology 2007; 4(1) (Jan/Feb 2007).

Choi SS, Kim SC, Han DJ, Clinical Outcome of Microsurgical Multiple Renal Artery Reconstruction in Renal Transplantation, J Korean Soc Transplant, 1997; 11(1): 81-94.

\section{How to cite this article:}

Richard Sungura, Callen Onyambu and Ian Mathenge. 2018. The CT Angiographic Prevalence of Renal Accessory Arteries in Kenya. Int.J.Curr.Microbiol.App.Sci. 7(01): 2745-2754. doi: https://doi.org/10.20546/ijcmas.2018.701.329 